\title{
Long-Term Sustainability in Global Higher Education Partnerships
}

\author{
Michael Lanford
}

\section{Introduction}

The creation of a global partnership in education requires a considerable investment of time and resources, yet comparatively little attention is given to long-term sustainability. This is surprising because, even when partnerships make excellent "common sense," long-term sustainability can be negatively impacted by a number of factors, including inequitable levels of commitment, confusion about the partnership's objectives, and/or cultural misunderstandings [1-3]. Moreover, the process of leveraging the necessary expertise, resources, and human capital to forge a partnership is both time-consuming and costly [4, 5].

Drawing from extant literature on global research partnerships that detail the firsthand experiences of international branch campuses, transnational education agreements, research collaborations, and other multinational consortia arrangements, this chapter first identifies four specific threats to long-term sustainability. The first threat involves divergent motivations and goals for the partnership. The second threat is inadequate planning and funding volatility, especially in instances when a partnership is overly reliant on one source of funding and is susceptible to market forces. The third threat addresses the issue of leadership turnover and a lack of formal and informal leaders from within the partnership. The fourth threat concerns poor staff morale as the result of an over-reliance on part-time employment; limited opportunities for individual advancement; and/or differing expectations for shared governance, faculty duties, and academic freedom.

Afterward, the chapter proposes four conditions that can improve the prospects of long-term sustainability for colleges and universities interested in stable, mutually beneficial global partnerships. First, a careful, transparent analysis of both institutions' organizational cultures is essential so

M. Lanford ( $\square)$

University of North Georgia, Atlanta, USA

e-mail: Michael.Lanford@ung.edu that an alignment in motivations and goals for both parties can be fostered. Second, multiple funding sources are vital, along with a strategic plan that outlines the projected duration of the partnership, prospects for deeper synergies, and entrepreneurial ventures. Third, shared leadership responsibilities among multiple individuals ensure consistent performance amidst turnover and change. Fourth, an environment that promotes dialog and opportunities for professional growth must be cultivated so that individuals feel like vested members of the partnership, concurrent with their membership in their respective disciplinary and professional communities.

As a final matter, the chapter considers two ethical issues pertinent to contemporary global partnerships. First, it argues that global partnerships should not simply exist in a vacuum, with benefits exclusively held by the members of the partnership. Instead, a global partnership should also forge a charter with society, fulfilling higher education's traditional outreach, instructional, and research missions so that the continued relevance of the partnership is apparent to internal and external stakeholders from a variety of backgrounds and experiences. Second, it maintains that activities related to innovation and entrepreneurship should be considered from the standpoint of the public good and conducted in a transparent manner, particularly if potential conflicts of interest might arise.

\section{Threats to Long-Term Sustainability}

In the early 1990s, researchers from the fields of business and marketing established an empirical basis for understanding why transnational collaborations either thrive or deteriorate over time. These researchers were motivated by a sense that globalization was rapidly transforming international trade, fostering a sense of interconnectedness between previously distant cultures, and encouraging competition for intellectual property and cheap labor between individual corporations 
and nation-states [6]. Therefore, they felt that new theoretical frameworks and data were necessary to depict changing business practices in a world of amplified entrepreneurial ventures and remarkable instability in labor markets.

Their conclusions were consistent in that healthy communication channels and trust were repeatedly found to be crucial for a productive and sustainable transnational relationship [7-10]. Collaborations that did not have these two essential ingredients were unlikely to survive threats to long-term sustainability that emerged at a surprisingly rapid pace, even during early interaction periods between stakeholders. Subsequent studies of global higher education partnerships have exhibited similar results, and four themes emerge from this evolving literature.

\subsection{Divergent Motivations and Goals}

The earliest factor highlighted by researchers concerned shared motivations and goals for the partnership [11]. As Heffernan and Poole discovered in their late-1990s studies of Australian universities' transnational partnerships, "quite simply, where there was a mismatch between the Australian university and the overseas education provider on the primary objectives and vision for the relationship, deterioration and potential termination in the relationship often occurred" [12]. In more recent years, the fate of several international branch campuses has suffered from similar mismatches between the aspirations of the home institution and the interests of the host country.

For example, the University of Nevada at Las Vegas (UNLV) offered undergraduate and graduate degrees in hospitality management and executive education for nearly ten years in the city-state of Singapore through an initially successful international branch campus venture. However, the branch campus was torn between the ambitions of UNLV (to establish a more comprehensive institution in an area perceived to have substantial economic promise and student talent) and the more circumspect plans of Singapore (to develop their own hospitality management program that could produce skilled labor for the city centerpiece Marina Bay Sands resort). Once the Singapore government no longer needed the expertise of UNLV's hospitality program, the international branch campus was forced to financially support itself through student tuition revenue. In subsequent years, the UNLV Singapore suffered from low visibility and paltry student enrollment, so it summarily closed [13].

\subsection{Inadequate Planning and Funding Volatility}

Institutions in Western nations where state funding for higher education has precipitously declined in recent years have been particularly keen to view global partnerships as an opportunity to generate much-needed income [14]. For example, Monash University in Australia unveiled international branch campuses in Malaysia and South Africa after its 1999 strategic development plan cited a need for greater institutional self-reliance in the face of decreased government funding [15]. Nevertheless, if a partnership is overly reliant on one source of funding, it could be upended by market forces, causing each of the vested parties to question their long-term commitment.

Wilkins and Huisman have further observed that some global partnerships, in the rush for alternative sources of revenue, have failed to adequately "understand the cultures and business practices in the regions they would like to operate" [16]. Drawing upon Simon Marginson's conceptualization of the Confucian higher education model in Southeast Asia [17], they explain how an incomplete understanding of cultural and political forces could result in frustration:

In countries such as China, Korea, and Singapore, the Confucian model molds higher education systems. Although foreign higher education institutions might benefit from high levels of family commitment to investment in higher education, they need to be aware that the government retains tight control over policy, planning, and funding [16].

Additionally, regional differences in contract law, hiring practices, and financial accounting practices cause instability for global partnerships [18, 19]. As a result, global partnerships that are created without substantial planning and an interrogation of regional cultures and national regulatory frameworks are unlikely to succeed beyond the first few years.

\subsection{Leadership Turnover and Instability}

For global partnerships to remain viable, leaders must carefully balance competing demands from external and internal stakeholders who are likely to have different agendas and visions for the partnership. For instance, the host institution or country (an external stakeholder from the perspective of the partnering institutions) may want to control resources and influence hiring practices. Internal stakeholders, in turn, are likely to feel protective about outside influences over curricula, research programs, and branding efforts. For these reasons, leadership stability is extremely important in maintaining a consistent vision and trajectory for a global partnership [20].

Unfortunately, global partnerships have historically witnessed substantial turnover in administrative and executive positions. Further, the recruitment and retention of knowledgeable administrators essential to the partnership can prove to be difficult [21]. The pool of individuals who have 
the global perspective and administrative background to lead a transnational partnership is relatively small. And yet, even the individuals who have the necessary experience to lead a global partnership may be loath to rebuild professional contacts in a new environment while uprooting their domestic partners and children from their professional careers and extended families.

As a final note, organizations can have a variety of expectations concerning leadership norms. Educational institutions, however, are different from many organizations in that a certain degree of freedom and collegiality is frequently expected by administrators and executives. Some may even be attracted to a global partnership specifically because they think greater workplace freedom may result from a group that is loosely coupled to multiple organizations, rather than intricately tied to a single institution [22].

Nonetheless, Anatoly Oleksiyenko has wisely cautioned that "corporate abuse emerges and is sustained primarily in zones of alienation - places with poorly designed academic organization, which fail to safeguard academic freedom, respect, and healthy collegial relations" [23]. The specific location where a global partnership largely conducts its work may have a culture that is more entrenched in hierarchical decision-making, and it could find its momentum stymied by frustrated employees who are used to greater independence in their previous jobs.

\subsection{Poor Faculty and Staff Morale}

Similar to the topic of leadership, Phillip Altbach has argued that recruiting and keeping faculty talent in global partnerships is the "greatest problem of sustainability":

[Faculty are] reluctant to leave their work, especially in the sciences. Junior faculty worry that overseas teaching will not serve their chances for promotion. Concerns about the education of children, employment of spouses, and other family issues also intervene. Even in cases where additional remuneration and other benefits are offered, it is frequently difficult to lure professors overseas. The problem is exacerbated over time. The relatively small number of home-campus faculty willing to relocate is restricted and quickly exhausted [24].

It is also known that the expectations of shared governance [25], faculty duties and participation [26], and academic freedom [27] may differ significantly among cross-border partners. This leads to cognitive dissonance among faculty who assume that the governance, service expectations, and freedom they experienced in their past institutional environments will continue unabated in a different cultural realm.

Since full-time faculty are often difficult to recruit for a global partnership, part-time faculty are frequently hired to fill teaching (and occasionally research) positions. However, an over-reliance on part-time faculty could limit teaching effectiveness, research productivity, and opportunities for individual advancement [28]. Part-time employees are also less likely to commit to a single institution. Compounding the problem is the fact that there is generally an unwillingness for global partnerships to be forthright about the challenges faculty will face in a foreign environment [29].

\section{Improving the Prospects for Long-Term Sustainability}

Given the confluence of these challenges, one might reasonably wonder if a global partnership is all but doomed beyond the first couple of years. This chapter, though, takes a different position. It contends that the threats to long-term sustainability outlined in the previous section can be ameliorated, but only if careful steps are taken to plan the future of the partnership, determine the organizational culture, distribute leadership responsibilities, and promote open dialog and professional growth.

\subsection{Alignment in Motivations and Goals for Both Parties}

He and Wilkins have suggested that to achieve legitimacy, international branch campuses have been compelled to "follow the local regulations of either the host country government or the quality assurance bodies," creating a situation where "the curriculum of the international branch campus must conform to the local standards" [30]. Thus, any type of global partnership is placed in a bind, whereby different legitimacy building strategies must be strategically considered. Some may argue that the partnership should simply conform to local practices, as He and Wilkins have documented. Others may assert that the partnership can establish independence if nearby institutional forces are weak and there is a low dependence on local resources.

This chapter instead contends that both parties need to have a similar investment in the motivations and goals of a partnership. For this to occur, at least three steps should be undertaken. First, a careful, open analysis should be conducted of both institutions' organizational cultures. Location can certainly influence this discussion; as described by Healey, "transnational education partnerships often operate in the rapidly growing economies of the Middle-East and Asia, where the linguistic, cultural, political, and legislative environments are very foreign to those of the exporting universities" [31].

Second, an equitable distribution of staff and coherent hiring practices should be cultivated. When too many employees come from one institution, the strengths of the partnership (e.g., diversity of ideas, a multicultural 
perspective) are diluted. Also, there is a risk that the organizational culture and mission statement will be undermined by the belief systems and past experiences of the majority group.

Third, the joint development of a mission statement should guide partnership activities. For all educational institutions, mission statements are of exceptional significance, as they can regulate the allocation of resources, accentuate certain organizational activities, and provide a sense of clarity during turbulent times. Without a clear mission, the partnership may lack coherence, and stakeholders will question its relevance.

\subsection{Careful Planning and Multiple Funding Sources}

Along with the development of a mission statement, a strategic plan should outline the projected duration of the partnership. In a study of 60 global higher education partnerships, Mwangi found "ninety percent of partnership stakeholders cited that a critical aspect of a successful partnership was the deliberate time and attention given to planning before implementation as it allowed for the development of effective and realistic goals for the project" [32]. Thus, the strategic plan should be formulated well before any official partnership activities take place and substantial financial resources are apportioned. By the same token, all institutions should have relatively equitable investments - of both money and resources - in the success of the partnership. As the strategic plan is developed, prospects for deeper synergies, entrepreneurial ventures, and/or other partners should be identified.

\subsection{Shared Leadership Responsibilities}

If global partnerships are destined to have significant leadership turnover, then it may appear virtually impossible to cultivate a consistent institutional identity and nurture values endemic to the organization. One solution, however, is to adopt distributed leadership theories that encourage individuals throughout the organization to become experts at specific areas essential for daily operations while concurrently developing leadership skills [33]. While no one leadership style is ideal for every organizational culture, the sharing of leadership responsibilities is important for reliable performance amidst turnover and change. This is especially true for relatively small organizations, like global partnerships, that have difficulty in cultivating "buy-in" among employees.
The communication style of leaders should also be consistent and effective in the local context. As Borgos [29] has noted, "the success of an organization in part will depend on its ability to make connections within the host country and to manage its dependency on the foreign external environment in which it operates". Without leadership who can forcefully articulate the goals and values of the partnership, the host culture might face difficulties in delivering appropriate support.

As a final point, not all leaders of an institution hold titles that signify their leadership credentials. Every institution has discernible "informal" leaders who may not hold an explicit leadership role but are widely recognized by their peers as important representatives of employee sentiments and as conduits for information about institutional decisions. Any partnership that hopes to maintain a sense of continuity from one year to the next cannot ignore the influence and prominence of these "informal" leaders. Instead, an institution needs to identify both the "formal" and "informal" leaders within the organization so that strategic decisions are deliberated and implemented in a manner that makes people feel that their sentiments - and their hard work - are valued [34].

\subsection{Open Dialog and Professional Growth}

Finally, a global partnership should be an environment that promotes open dialog and encourages opportunities for individual professional growth. The expectations of governance, faculty activities, and free speech (for all members, including faculty, staff, and students) should be clear, especially if they differ from the expectations of the partners' campuses. In addition, it is essential to remember that researchers are members of the partnership and also members of their scholarly communities; they need to have opportunities for personal and professional growth in both spheres. For some individuals interested in developing their teaching expertise, this might mean participation and financial support for pedagogical seminars and instructional colloquia in different countries. For faculty who wish to maintain their research profile, grant funding support and institutional sponsorship of faculty and student research collaborations might be necessary.

Similarly, administrative and staff professionals will likely maintain a duality in which they devote substantial energy to the preservation of distant professional relationships while they further the immediate goals of the partnership. Such a division of roles should not be seen as a 
distraction; rather, it should be encouraged as a way to both develop the skills of partnership members and spread the activities of the partnership to new audiences [35].

\section{Establishing Legitimacy by Embracing Community}

Over the past 20 years, global higher education partnerships have expanded due to several motivating factors grounded in rational planning and global competition. From the perspective of the "host" country, a global partnership can be one vital component of a broader strategy to expand capacity in the higher education sector, develop a twenty-first-century workforce, encourage collaborative research, or enhance institutional prestige. From the perspective of the "exporting" institution, a global partnership can propel institutional branding efforts, forge international ties, lead to the recruitment of talented students and faculty, or simply be financially advantageous.

\subsection{Legitimacy Concerns}

Despite these potential benefits, global partnerships continue to suffer from internal and external legitimacy concerns. The faculty and staff of exporting institutions regularly question the purposes and value systems of global partnerships and, at times, actively campaign against their development. Those who work in a global partnership may not only feel distant from the activities and reward structures on their home campuses but also acutely aware of the opposition to their work. The benefits to the majority of people in the host country are also too frequently unclear, as global partnerships may appear to have little engagement with their surrounding communities [36].

Therefore, it is useful to ask if the discussion around global partnerships in higher education has been, to date, far too circumscribed by neoliberal philosophies that extol economic gain and competitive advantage. Partnerships are almost always formed between inherently unequal parties. One only needs to observe the number of global partnerships between institutions from wealthy nations and institutions from low-income countries, along with the resultant uneven levels of participation and individual agency [37]. The imbalances in North-South research collaborations that grant Northern researchers the ability to establish research priorities, dictate the theories to be deployed, and decide the methods to be utilized have also been well-documented [38].

Additionally, as Phillip Altbach and Jane Knight have cautioned, "globalization tends to concentrate wealth, knowledge, and power in those already possessing these elements" [39]. Authors have extended this analysis to observe that global partnerships and international branch campuses reify elite global university networks while having a limited (perhaps even negative) impact on educational equity and basic human rights, such as free speech and the protection of minoritized people [40-42].

Conversely, an increasing number of research studies have demonstrated that transnational higher education has a minimal, if not completely ineffectual, impact on local educational entities due to a lack of inter-institutional communication and knowledge exchange [43]. Global higher education partnerships have also tended to operate outside of traditional regulatory environments in that they operate as private entities (even when they receive public funding), and they have nebulous accountability to both their home institutions and their respective governments [44]. These findings are especially disquieting for those countries who hope global partnerships will stimulate education hubs, a region distinguished by an expansion of cross-border talent, knowledge production, and innovative ideas that can have immediate, tangible benefits for the local economy and society as a whole [45].

\subsection{Conceptualizing a Charter with Society}

Hence, this chapter takes a different conceptual perspective by asking a final question: What would it look like if global partnerships in higher education developed a charter with their respective societies?

As Kezar has compellingly argued, contemporary higher education is torn between key aspects of neoliberalism, such as private enterprise and economic enterprise, and traditional notions of the public good, where colleges and universities support local and regional communities through contributions to government, health care, primary education, and other social institutions [46]. However, it is important to emphasize that neoliberal values and the public good need not be in perpetual conflict. In fact, global higher education partnerships may need to refocus some of their neoliberal activities in service of the public good in order to establish greater legitimacy and assuage critics who feel such partnerships are only advancing the aspirations of elite actors and institutions.

One way to accomplish such a task is to perform educational outreach activities in local communities. Elsewhere, I have written about how international branch campuses can be too often viewed as cloistered communities that preserve valuable educational resources for a privileged few [47]. Global higher education partnerships could instead embrace, particularly in their mission statements, the responsibility to train globally minded citizens. Furthermore, outreach efforts 
could be maintained with local community organizations to provide support for marginalized groups that might otherwise be overlooked or exploited.

Second, the fruits of artistic endeavor and scientific development should be available to individuals in the community, as well as members of the partnership and sponsoring institutions. A global partnership should not have an exclusive focus on enriching the coffers of the institutional stakeholders. A long-term goal of greater access could be simultaneously developed so that the partnership is truly a hub for diverse backgrounds and perspectives - not just a multicultural collection of elite actors.

Third, activities related to innovation and entrepreneurship should be conducted in a transparent manner, particularly if they invite potential conflicts of interest. The temptation to monetize every innovation is understandable, given the competitive pressures of globalization, university rankings, and academic branding efforts. A compact with society, though, would weigh short-term benefits related to resources and prestige with the long-term sustainability of a partnership that is perceived as being vital for societal progress [48]. If an innovation or important medical discovery becomes too expensive for most people in the surrounding community to use, then the partnership has behaved no differently than a multinational corporation beholden to shareholders.

\section{Conclusion}

A global partnership in higher education can strengthen existing academic networks and business relationships [49], promote greater intercultural awareness [50], and open new opportunities for innovative research [51]. Despite their continued expansion, however, such partnerships are plagued by poor planning, sustainability problems, and legitimacy concerns. Many partnerships seem to be created only with a short-term perspective that is set up to take advantage of temporary financial windfalls and/or human capital that is susceptible to exploitation. Once the slightest difficulty threatens the partnership's survival, it may be ill-equipped to articulate a coherent mission, transition to alternative funding sources, rely on a combination of "formal" and "informal" leaders, or foster open dialog, each of which have been proven to sustain organizations for the long term.

Moreover, power dynamics between different transnational educational stakeholders remains a topic worthy of continued investigation. As this chapter has demonstrated, a global higher education partnership must carefully negotiate cultural expectations and norms, consider the perspectives of different partners, and ensure that communication channels are maintained, particularly for those who might reside in marginalized positions within the organization. What we have learned over the past two decades of global higher education partnerships is that competition too often obscures original intent - and the intent is to sustain a mutually beneficial alliance that will not only advance the dreams and ambitions of individuals within the organization, but ultimately benefit society as well.

\section{References}

1. Healey, N. (2018). The optimal global integration-local responsiveness tradeoff for an international branch campus. Research in Higher Education, 59(5), 623-649.

2. Healey, N. (2015). Towards a risk-based typology for transnational education. Higher Education, 69(1), 1-18.

3. Tierney, W. G., \& Lanford, M. (2015). An investigation of the impact of international branch campuses on organizational culture. Higher Education, 70(2), 283-298.

4. Knight, J. (2011). Education hubs: A fad, a brand, an innovation? Journal of Studies in International Education, 15(2), 221-240.

5. Oleksiyenko, A., \& Sá, C. (2010). Resource asymmetries and cumulative advantages: Canadian and U.S. research universities and the field of global health. Higher Education, 59(3), 367-385.

6. Held, D., McGrew, A., Goldblatt, D., \& Perraton, J. (1999). Global transformations: Politics, economics, and culture. Stanford, CA: Stanford University Press.

7. Anderson, J. C., \& Narus, J. A. (1990). A model of distributor firm and manufacturer firm working partnerships. Journal of Marketing, 54(1), 42-58.

8. Czepiel, J. (1990). Service encounters and service relationships: Implications for research. Journal of Business Research, 20, 13-21.

9. Morgan, R. M., \& Hunt, S. D. (1994). The commitment-trust theory of relationship marketing. Journal of Marketing, 58(3), $20-38$.

10. Webster, F. E. (1992). The changing role of marketing in the corporation. Journal of Marketing, 56(4), 1-17.

11. Heffernan, T., \& Poole, D. (2005). In search of "the vibe": Creating effective international education partnerships. Higher Education, 50(2), 223-245.

12. Heffernan, T., \& Poole, D. (2004). "Catch me I'm falling": Key factors in the deterioration of offshore education partnerships. Journal of Higher Education Policy and Management, 26(1), 75-90.

13. Weinman, J. (2019). The case of UNLV Singapore: Lessons learned from an international branch campus closure. Paper presented at the Comparative and International Education Society Annual Conference, San Francisco, USA.

14. Welch, A. (2011). Higher education in Southeast Asia: Blurring borders, changing balance. Abingdon: Routledge.

15. McBurnie, G., \& Pollock, A. (2000). Opportunity and risk in transnational education-Issues in planning for international campus development: An Australian perspective. Higher Education in Europe, 25(3), 333-343.

16. Wilkins, S., \& Huisman, J. (2012). The international branch campus as transnational strategy in higher education. Higher Education, 64(5), 627-645.

17. Marginson, S. (2011). Higher education in East Asia and Singapore: Rise of the Confucian model. Higher Education, 61 (5), 587-611.

18. Harding, L. M., \& Lammey, R. W. (2011). Operational considerations for opening a branch campus abroad. New Directions for Higher Education, 155, 65-78. 
19. Verbik, L. (2007). The international branch campus: Models and trends. International Higher Education, 46, 14-15.

20. Lane, J. (2011). Global expansion of international branch campuses: Managerial and leadership challenges. New Directions for Higher Education, 155, 5-7.

21. Shams, F., \& Huisman, J. (2014). The role of institutional dual embeddedness in the strategic local adaptation of international branch campuses: Evidence from Malaysia and Singapore. Studies in Higher Education, 41(6), 955-970.

22. Weick, K. E. (1976). Educational organizations as loosely coupled systems. Administrative Science Quarterly, 21(1), 1-19.

23. Oleksiyenko, A. (2018). Zones of alienation in global higher education: Corporate abuse and leadership failures. Tertiary Education and Management, 24(3), 193-205.

24. Altbach, P. (2010). Why branch campuses may be unsustainable. International Higher Education, 58, 2-3.

25. Healey, N. (2008). Is higher education in really "internationalizing?". Higher Education, 55(3), 333-355.

26. McBurnie, G., \& Ziguras, C. (2007). Transnational education: Issues and trends in off-shore higher education. London: Routledge.

27. Tierney, W. G., \& Lanford, M. (2014). The question of academic freedom: Universal right or relative term? Frontiers of Education in China, 9(1), 4-23.

28. Kinser, K., et al. (2010). The global growth of higher education. San Francisco: Wiley.

29. Borgos, J. (2016). Addressing sustainable international branch campus development through an organizational structure lens: A comparative analysis of China, Qatar, and the United Arab Emirates. Chinese Education and Society, 49(4-5), 271-287.

30. He, L., \& Wilkins, S. (2017). Achieving legitimacy in cross-border higher education: Institutional influences on Chinese international branch campuses in South East Asia. Journal of Studies in International Education, 22(3), 179-197.

31. Healey, N. (2018). The challenges of managing transnational education partnerships: The views of "home-based" managers vs. "in-country" managers. International Journal of Educational Management, 32(2), 241-256.

32. Mwangi, C. A. G. (2017). Partner positioning: Examining international higher education partnerships through a mutuality lens. Review of Higher Education, 41(1), 33-60.

33. Spillane, J. P. (2005). Distributed leadership. Educational Forum, 69(2), 143-150.

34. Tierney, W. G., \& Lanford, M. (2018). Institutional culture in higher education. In J. C. Shin \& P. N. Teixeira (Eds.), Encyclopedia of international higher education systems and institutions (pp. 1-7). Dordrecht: Springer.

35. Cai, L., \& Hall, C. (2016). Motivations, expectations, and experiences of expatriate academic staff on an international branch campus in China. Journal of Studies in International Education, 20(3), 207-222.

Open Access This chapter is licensed under the terms of the Creative Commons Attribution 4.0 International License (http:// creativecommons.org/licenses/by/4.0/), which permits use, sharing, adaptation, distribution and reproduction in any medium or format, as long as you give appropriate credit to the original author(s) and the source, provide a link to the Creative Commons license and indicate if changes were made.
36. Siltaoja, M., Juusola, K., \& Kivijärvi, M. (2018). "World-class" fantasies: A neocolonial analysis of international branch campuses. Organization, 1-23 (advance online publication).

37. Leng, P. (2016). Mutuality in Cambodian international university partnerships: Looking beyond the global discourse. Higher Education, 72(3), 261-275.

38. Koehn, P. H. (2013). Developments in transnational research linkages: Evidence from U.S. higher education activity. New Approaches in Educational Research, 3(2), 52-58.

39. Altbach, P., \& Knight, J. (2007). The internationalization of higher education: Motivations and realities. Journal of Studies in International Education, 11(3-4), 290-305.

40. Altbach, P., \& Hazelkorn, E. (2017). Pursuing rankings in the age of massification: For most-forget about it. International Higher Education, 89, 8-10

41. Pusser, B., \& Marginson, S. (2013). University rankings in critical perspective. Journal of Higher Education, 84(4), 544-568.

42. Tierney, W. G., \& Lanford, M. (2017). Between massification and globalization: Is there a role for global university rankings? In E. Hazelkorn (Ed.), Global rankings and the geopolitics of higher education (pp. 295-308). Oxford: Routledge.

43. Ding, X. (2018). Marginal revolution: The impact of transnational education on higher education in host countries: A case study of China. Higher Education Policy, 1-22. https://doi.org/10.1057/ s41307-018-0089-5.

44. Lane, J., \& Kinser, K. (2008). The private nature of cross-border higher education. International Higher Education, 53, 11.

45. Knight, J. (2018). International education hubs. In P. Meusburger, M. Heffernan, \& L. Suarsana (Eds.), Geographies of the university (pp. 637-655). Cham: Springer.

46. Kezar, A. (2004). Obtaining integrity? Reviewing and examining the charter between higher education and society. Review of Higher Education, 27(4), 429-459.

47. Lanford, M., \& Tierney, W. G. (2016). The international branch campus: Cloistered community or agent of social change? In D. Neubauer, J. Hawkins, M. Lee, \& C. Collins (Eds.), The Palgrave handbook of Asia Pacific higher education (pp. 157-172). New York: Palgrave Macmillan.

48. Tierney, W. G., \& Lanford, M. (2016). Conceptualizing innovation in higher education. In M. B. Paulsen (Ed.), Higher education: Handbook of theory and research (Vol. 31, pp. 1-40). Dordrecht: Springer.

49. Kim, J., \& Celis, S. (2016). Global partnership as a strategy for internationalisation: MBAs in Latin America and Asia and Oceania. Higher Education Policy, 29(3), 355-378.

50. DeLong, M., et al. (2011). Cultural exchange: Evaluating an alternative model in higher education. Journal of Studies in International Education, 15(1), 41-56.

51. Tierney, W. G., \& Lanford, M. (2016). Cultivating strategic innovation in higher education. New York: TIAA-CREF Institute.

The images or other third party material in this chapter are included in the chapter's Creative Commons license, unless indicated otherwise in a credit line to the material. If material is not included in the chapter's Creative Commons license and your intended use is not permitted by statutory regulation or exceeds the permitted use, you will need to obtain permission directly from the copyright holder. 